\title{
Instability at microsatellite sequences in spontaneously aborted human embryos provides evidence for a novel mechanism for recurrent miscarriages
}

\author{
H. KIARIS ${ }^{1,2}$, E. KOUMANTAKIS ${ }^{1}$, M. ERGAZAKI ${ }^{1,2}$, S. SIFAKIS ${ }^{1,2}$ and D.A. SPANDIDOS ${ }^{1,2}$ \\ ${ }^{1}$ Medical School, University of Crete, Heraklion; ${ }^{2}$ Institute of Biological Research and Biotechnology, \\ National Hellenic Research Foundation, Athens, Greece
}

Received June 6, 1995; Accepted July 14, 1995

\begin{abstract}
Several factors have been proposed to confer a risk for abortion of the embryo. However, the aetiology of spontaneous abortions remains unclear. In the present study we investigated if an increased mutational rate occurs in the embryonic tissue and whether this phenomenon is associated with recurrent miscarriage. The mutational rate was assessed in 30 spontaneously aborted embryos using a bank of 8 highly polymorphic microsatellite markers, each one located on a different chromosome. The microsatellite sequences of DNA extracted from distal sites of each embryo were amplified by the polymerase chain reaction and the electrophoretic patterns were compared. Shifts in the mobility of the microsatellites indicating instability were scored for 12 among $30(40 \%)$ specimens, thus suggesting that microsatellite instability (MI) is a relatively common feature of spontaneously aborted embryonic tissues. Association was found between instability and the absence of normal childbirth: 11 among 18 cases without a normal childbirth exhibited evidence of MI while only one among 12 cases with normal childbirth was positive for MI. Our results suggest that instability at microsatellite sequences which indicate decreased fidelity in DNA replication and repair are associated with the recurrent abortion of the embryo, particularly in cases without a normal childbirth.
\end{abstract}

\section{Introduction}

The precise mechanism of recurrent abortions remains obscure, although several factors have been proposed to confer in the pathogenesis of this phenomenon (reviewed in ref. 1). These factors include anatomical disorders $(2,3)$, chromosomal alterations and genetic causes (4-7), endocrine factors $(8,9)$, reproductive tract infections $(10)$, immunological

Correspondence to: Professor D.A. Spandidos, Institute of Biological Research and Biotechnology, National Hellenic Research Foundation, 48 Vas. Constantinou Ave., Athens, 116 35, Greece

Key words: microsatellite instability, spontaneous abortions
(11) or even psychological causes (12). However, a significant subset of the cases is not associated with any of the forementioned situations, indicating the presence of additional factors that confer to the recurrent rejection of the embryo. In the present study we investigated whether decreased fidelity in DNA replication, reflected in the instability of the microsatellite DNA, may play a role in the pathogenesis of recurrent abortions.

Microsatellite instability (MI) reflects elevated mutational rate. Initially this phenomenon was recognised in colorectal cancer (13-15) and later extended to other sporadic tumours including endometrial (16), breast (17), lung (18) and head and neck cancer $(19,20)$. The precise mechanism of this alteration remains unknown, however, it has been proposed that it is the result of decreased fidelity in DNA replication and repair through strand misalignment (21). Although these sequences are functionally neutral, MI reflects an increased mutational rate that may affect other genomic sequences including active genes with consequences in the normal cell growth and differentiation.

The detection of MI in aborted embryonic tissues would be a challenging explanation for the rejection of the embryo, since the elevated mutational rate of this phenomenon, suggests the mutational activation (or inactivation) of genes that may cause the termination of the pregnancy. Thirty aborted embryonic tissues were analysed by means of polymerase chain reaction (PCR) using a bank of 8 polymorphic microsatellite markers and demonstrated that this subchromosomal alteration is a relatively common event in recurrent miscarriages.

\section{Materials and methods}

Specimens and DNA extraction. Thirty spontaneously aborted embryonic tissues were obtained from the University Hospital of Heraklion, Department of Gynecology. All the specimens consisted of at least $95 \%$ embryonic tissue. Tissues were taken at the time of rejection and frozen in liquid nitrogen until DNA extraction.

Genomic DNA was extracted from the frozen tissues as previously described (20). Two sections from distal sites of the embryo were obtained from each specimen. DNA samples were stored at $4^{\circ} \mathrm{C}$. 
D19S49

Case No.
1026

A B 11

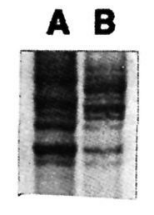

HRM

17

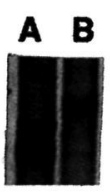

D13S175

26

\section{D6S344}
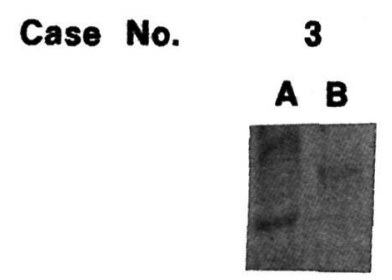

10

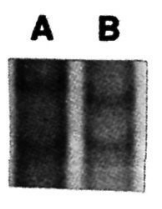

27

A $\mathbf{B}$

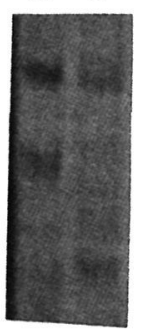

Figure 1. Representative examples of specimens exhibiting microsatellite instability. A and B correspond to distal sites of the embryonic tissue. Only cases with an apparent shift in the mobility of the microsatellites were interpreted as MI positive. Cases with allelic imbalance could indeed be due to the generation of a novel microsatellite allele but also the result of a chromosomal aberration (trisomy or aneuploidy). However, in several cases allelic imbalance co-existed with a shift, i.e. in cases 3,10 and 17 for the markers D6S344, D19S49 and HRM respectively. In the rest of the cases a shift in the mobility of the microsatellites was apparent by comparing the two electrophoretic patterns.

Table I. Markers used for the assessment of MI in 30 aborted embryonic tissues, location and incidence of MI.

\begin{tabular}{lcc}
\hline Marker & Chromosome & Cases with alteration (\%) \\
\hline D6S344 & 6 & $5(17)$ \\
D7S531 & 7 & 0 \\
HRM & 11 & $2(7)$ \\
D12S94 & 12 & $1(3)$ \\
D13S175 & 13 & $3(10)$ \\
TCRD & 14 & $1(3)$ \\
THRA1 & 17 & $5(17)$ \\
D19S49 & 19 & $2(7)$ \\
\hline
\end{tabular}

Microsatellite analysis. Eight microsatellite markers, each one located on a different chromosome, were used (Table I). All the markers were dinucleotide repeats apart from the marker HRM which is a six nucleotide repeat (19). PCR reactions were performed in a $12.5 \mu$ l reaction volume containing approx. $100 \mathrm{ng}$ of genomic DNA, $500 \mu \mathrm{M}$ dNTPs, $10 \mathrm{pmol}$ of each forward and reverse primer, $1.25 \mu \mathrm{l}$ of $10 \mathrm{X}$ buffer $(670 \mathrm{mM}$ Tris- $\mathrm{HCl} \mathrm{pH} 8.5,166 \mathrm{mM}$ ammonium sulphate, $67 \mathrm{mM} \mathrm{MgCl}, 1.7 \mathrm{mg} / \mathrm{ml}$ bovine serum albumin, $100 \mathrm{mM}$ B-mercaptoethanol and $1 \%(\mathrm{w} / \mathrm{v})$ Triton-X-100) and $0.3 \mathrm{U}$ Taq polymerase. The reactions were denatured for $5 \mathrm{~min}$ at $95^{\circ} \mathrm{C}$ and the DNA was subsequently amplified for 28 cycles at $95^{\circ} \mathrm{C}, 58-60^{\circ} \mathrm{C}$ and $72^{\circ} \mathrm{C}, 30 \mathrm{sec}$ each step. $5 \mu \mathrm{l}$ of the PCR product was electrophoresed in a $10 \%$ polyacrylamide gel and silver stained. MI was scored after the comparison of the electrophoretic pattern of the microsatellite markers amplified from the paired DNA preparations that corresponded to different sites of the embryo. Only cases with a mobility shift were interpreted as positive for MI and not cases with an allelic imbalance because this might be due to the chromosomal aberrations.

\section{Results}

The incidence of MI was assessed in 30 spontaneously aborted embryonic tissues using a bank of 8 polymorphic microsatellite markers. MI was apparent in $12(40 \%)$ among 30 cases (Table II). Six specimens exhibited evidence of one affected marker only, five specimens of two affected markers while one case exhibited MI in 3 microsatellite markers.

In several cases MI was accompanied by allelic imbalance (Fig. 1) which is in agreement with the observation that chromosomal aberrations are common in aborted material (4). A similar phenomenon of concurrent MI and allelic imbalance was described in tumour specimens from head and neck cancer (20).

Association was investigated between MI and the following clinicopathological parameters: Age of the embryo, age of the mother, number of previous spontaneous abortions, normal childbirth and the presence of IgG and IgM antibodies for the herpes simplex virus (HSV) type 1 and type 2 or the human cytomegalovirus (CMV). Association was found only with the existence of a normal childbirth 
Table II. Microsatellite instability in spontaneously aborted embryonic tissues.

\begin{tabular}{|c|c|c|c|c|c|c|c|c|c|c|c|}
\hline \multirow{3}{*}{$\begin{array}{l}\text { Specimen } \\
\text { no. }\end{array}$} & \multirow{3}{*}{$\begin{array}{l}\text { Age of the } \\
\text { embryo } \\
\text { (weeks) }\end{array}$} & \multirow{3}{*}{$\begin{array}{l}\text { Age of the } \\
\text { mother } \\
\text { (years) }\end{array}$} & \multirow{3}{*}{$\begin{array}{l}\text { No. of } \\
\text { spontaneous } \\
\text { abortions }\end{array}$} & \multirow{3}{*}{$\begin{array}{l}\text { Normal } \\
\text { childbirth }\end{array}$} & \multicolumn{4}{|c|}{$\mathrm{HSV}^{\mathrm{a}}$} & \multirow{2}{*}{\multicolumn{2}{|c|}{$\mathrm{CMV}^{\mathrm{a}}$}} & \multirow{3}{*}{$\begin{array}{l}\text { MI affected } \\
\text { markers }\end{array}$} \\
\hline & & & & & \multicolumn{2}{|c|}{ type 1} & \multicolumn{2}{|c|}{ type 2} & & & \\
\hline & & & & & IgM & IgG & $\operatorname{IgM}$ & IgG & IgM & $\operatorname{IgG}$ & \\
\hline 1 & 10 & 35 & 1 & + & - & - & - & - & - & - & $\begin{array}{l}\text { TCRD } \\
\text { D13S175 }\end{array}$ \\
\hline 2 & 10 & 24 & 1 & - & + & + & - & + & - & + & D13S175 \\
\hline 3 & 18 & 30 & 2 & - & - & + & - & + & - & + & D6S344 \\
\hline 4 & 16 & 26 & 2 & - & - & + & - & + & - & - & \\
\hline 5 & 10 & 19 & 1 & - & - & + & - & + & - & + & \\
\hline 6 & 14 & 22 & 1 & - & - & + & - & + & - & + & $\begin{array}{l}\text { THRA1 } \\
\text { D12S94 }\end{array}$ \\
\hline 7 & 8 & 39 & 1 & + & - & + & - & + & - & + & \\
\hline 8 & 17 & 27 & 1 & + & - & + & - & + & - & - & \\
\hline 9 & 8 & 35 & 1 & + & - & + & - & + & - & - & \\
\hline 10 & 10 & 40 & 1 & - & - & + & - & + & - & + & $\begin{array}{l}\text { D19S49 } \\
\text { D6S344 }\end{array}$ \\
\hline 11 & 8 & 37 & 1 & + & - & + & - & + & - & - & \\
\hline 12 & 10 & 37 & 1 & - & - & + & - & + & - & + & THRA1 \\
\hline 13 & 7 & 40 & 1 & + & - & + & - & + & - & + & \\
\hline 14 & 8 & 24 & 1 & - & - & + & - & + & - & + & HRM \\
\hline 15 & 11 & 35 & 2 & - & - & + & - & + & - & - & \\
\hline 16 & 11 & 26 & 1 & - & + & + & - & + & - & - & D6S344 \\
\hline 17 & 9 & 28 & 1 & - & - & + & - & + & - & - & $\begin{array}{l}\text { THRA1 } \\
\text { HRM }\end{array}$ \\
\hline 18 & 8 & 17 & 1 & + & - & + & - & + & + & + & \\
\hline 19 & 7 & 26 & 1 & + & + & + & + & + & + & + & \\
\hline 20 & 8 & 25 & 1 & - & + & + & - & + & - & + & \\
\hline 21 & 10 & 31 & 1 & - & - & + & - & + & - & + & THRA1 \\
\hline 22 & 12 & 17 & 1 & - & - & - & - & - & - & - & \\
\hline 23 & 8 & 35 & 2 & + & - & + & - & + & + & + & \\
\hline 24 & 10 & 33 & 1 & + & - & - & - & - & - & + & \\
\hline 25 & 11 & 23 & 1 & - & - & + & - & + & - & + & \\
\hline 26 & 12 & 24 & 1 & - & - & + & - & + & - & + & $\begin{array}{l}\text { D19S49 } \\
\text { D6S344 } \\
\text { D13S175 }\end{array}$ \\
\hline 27 & 11 & 20 & 1 & - & + & + & + & + & - & + & $\begin{array}{l}\text { D6S344 } \\
\text { THRA1 }\end{array}$ \\
\hline 28 & 10 & 31 & 1 & - & - & + & - & + & - & - & \\
\hline 29 & 10 & 35 & 2 & + & - & - & - & - & - & + & \\
\hline 30 & 6 & 22 & 1 & + & - & + & - & + & - & + & \\
\hline
\end{tabular}

aDetermined by ELISA.

Table III. MI aborted embryonic tissues in association with a normal childbirth in the past.

Total no. No. of specimens of specimens with MI (\%)

No. of specimens with

12

$1(8)$

normal childbirth

No. of specimens without

18

$11(61)$
(Table III): 11 out of 18 cases (61\%) without normal childbirth exhibited evidence of $\mathrm{MI}$ in at least one microsatellite marker while only one among 12 cases (8\%) with normal childbirth was positive for MI which is highly significant $\left(\chi^{2}, P<0.01\right)$. This finding indicates that indeed MI or decreased fidelity in DNA replication plays an aetiological role in the rejection of the embryo, particularly in the absence of a pre-existing normal childbirth. The incidence of MI varied considerably in different microsatellite markers: Two markers (THRA1 and D6S344) exhibited evidence of instability in 5 cases while the marker D7S531 was negative for all the cases tested (Table III). This may indicate that 
different markers exhibit variable levels of sensitivity for instability.

\section{Discussion}

The precise mechanisms that result in the rejection of the embryonic fetus remain unclear. Factors with aetiological association with this phenomenon include anatomical disorders, genetic alterations (mainly studied at the chromosomal level), endocrine factors, the presence of infectious agents, immunological and psychological causes (1).

In the present study we demonstrated that instability of microsatellite DNA sequences is a detectable phenomenon in spontaneously aborted material and probably aetiologically associated with the pathophysiology of the recurrent miscarriage.

We analysed the incidence of MI in 30 spontaneously aborted embryonic tissues, using a bank of 8 highly polymorphic microsatellite markers. The methodological approach of our study exhibited two main limitations that may result in the underestimation of the results: (a) We scored as $\mathrm{MI}^{+}$only the cases with a shift in the mobility of the microsatellite alleles and not those with transitions from heterozygosity to homozygosity because this could also be due to an allelic imbalance which is a common event in aborted material. (b) We compared the PCR amplification patterns of DNA extracted from distal sites of the embryonic body. However, this does not guarantee that the corresponding cells arise from distal cell clones in the ontogenesis of the embryo and thus increase the probability for the detection of MI.

Regardless of the forementioned limitations, we detected MI in at least one marker in $40 \%(12 / 30)$ of the cases. The absence of normal control tissue due to ethical restrictions did not permit the assessment of the background incidence of MI in normal embryos. However, in vitro experiments in cell lines have demonstrated that the MI rate in normal cells (corresponding to the background levels of MI) is less than $10^{-5}$ per allele per duplication (22) which is very low and argues strongly in favour of the high MI incidence in spontaneously aborted embryos. It might be argued that MI in particular cases represents an artefact of the methodological approach, i.e. particular DNA preparations could have significant proportion of maternal DNA and thus MI would actually be the result of the comparison between the maternal and the embryonic pattern. However, in this case we should expect to observe MI in the samples to affect all the markers tested, but this did not occur and thus MI, indeed reflected instability at DNA microsatellite sequences of the aborted embryonic tissue.

A strong trend was found between MI and the absence of a normal childbirth: MI was more common (11 out of 18 cases) in the cases without a normal childbirth, while in the cases with at least one childbirth evidence of MI was found in only one among 12 cases $\left(\chi^{2}, \mathrm{P}<0.01\right)$. These findings associate the replication error phenotype $\left(\mathrm{MI}^{+}\right)$with the disability of normal childbirth.

Although the microsatellite DNA sequences are transcriptionally inactive, instability may have consequences in the nucleosome phasing, in erasing genomic imprinting, inducing frameshifts or mutating enhancers or promoters. Furthermore, we may postulate that the apparently high mutational rate affects other active genomic sequences which may result in the termination of the pregnancy. In the case of colonic tumours, TGF- $\beta$, type II receptor was shown to be among the main targets of instability (23). Similarly, the detection of the target(s) of MI in the case of recurrent miscarriage is required, in order to evaluate the significance of this phenomenon. It would also be informative to assess the DNA repair efficiency in spontaneously aborted embryonic tissues by functional assays. This would be a direct confirmation (or rejection) of the hypothesis that $\mathrm{MI}$ in these specimens is the result of decreased fidelity in DNA repair efficiency. A similar approach was followed for cases with familial colorectal cancer and cell lines that exhibited MI and indeed it was found that the replication error phenotype was accompanied with decreased efficiency in the repair of DNA (24).

Instability at simple repeated sequences has been found not only in tumours but also in neurodegenerative diseases such as Huntington's disease, the fragile $\mathrm{X}$ syndrome, etc. (25). A significant difference between these types of instability is that MI in cancer affects almost all the markers examined, while in the case of the neurodegenerative diseases, instability is detectable at particular markers only, probably associated with specific genes. The demonstration of $\mathrm{MI}$ in aborted material reveals similarities with the phenotype of the tumour cells and can be interpreted as the destabilisation of the whole genome due to decreased DNA repair efficiency.

Apart from the understanding of the basic mechanism of the spontaneous abortion, the detection of MI in recurrent miscarriages may have important clinical applications. These include the evaluation of a probability for the rejection of the embryo, particularly in the cases without a normal childbirth and thus the assessment of the risk of a particular pregnancy. It would also be of particular interest to assess MI in aborted material in comparison with the haplotype of both parents and examine whether instability occurs more frequently in the maternally or paternally derived allele. This may provide evidence for a type of imprinting in instability or alternatively for the stage (gametic or postzygotic) this phenomenon was initiated. The development of sensitive molecular techniques makes this methodology applicable since MI can be detected even from a single DNA preparation, after the serial dilution of the sample (26).

Apart from MI an additional alteration at the DNA level is proved to play a significant role in the recurrent abortions. Chromosomal aberrations are involved in approximately $50 \%$ of the cases, particularly in the first trimester of pregnancy (1). The present findings suggest that genomic instability is extended to the subchromosomal level as well, affecting microsatellite sequences.

In the present investigation we analysed the incidence of MI in spontaneously aborted embryonic tissues and showed that MI is a detectable phenomenon in these specimens. Therefore we postulate that MI possesses an aetiological role in recurrent rejection of the embryo. The precise molecular mechanism and the clinical application of these findings should be clarified with further experiments. 


\section{References}

1. Stirrat GM: Recurrent miscarriage II. Clinical associations, causes, and management. Lancet 336: 728-733, 1990.

2. Stray-Pedersen B and Stray-Pedersen S: Etiologic factors and subsequent reproductive performance in 195 couples with prior history of habitual abortion. Am J Obstet Gynecol 148: 140146, 1984.

3. Harger JH, Archer DF, Marchese SG, Muracca-Clemens M, Garver KL: Etiology of recurrent pregnancy losses and outcome of subsequent pregnancies. Obstet Gynecol 62: 574-581, 1983.

4. Olson SB and Magenis RE: Cytogenetic aspects of recurrent pregnancy loss. Semin Reprod Endocrinol 6: 191-202, 1988.

5. McCreanor HR, O'Malley FM and Reid RA: Trisomy in abortion material. Lancet 2: 972-973, 1973.

6. McDonough PG: The role of molecular mutation in recurrent euploidic abortion. Semin Reprod Endocrinol 6: 155-164, 1988.

7. Lehrer S, Sanchez M, Song HK, et al: Oestrogen receptor Bregion polymorphism and spontaneous abortion in women with breast cancer. Lancet 335: 622-624, 1990.

8. Sagle M, Bishop K, Ridley N, et al: Recurrent early miscarriage and polycystic ovaries. Br Med J 297: 1027-1028, 1988.

9. Kalter H: Diabetes and spontaneous abortion (a historical review). Am J Obstet Gynecol 6: 1243-1253, 1987.

10. Nassens A, Foulon W, Cammu H, et al: Epidemiology and pathogenesis of Ureaplasma urealyticum in spontaneous abortion and early pre-term labour. Acta Obstet Gynecol Scand 66: 513-516, 1987.

11. Cowchock S, Smith RJ, Gocial B: Antibodies to phospholipids and nuclear antigens in patients with repeated abortions. Am J Obstet Gynecol 155: 1002-1010, 1986.

12. Stray-Pedersen B, Stray-Pedersen S: Recurrent abortion: the role of psychotherapy. In: Early Pregnancy Loss: Mechanism and Treatment. Beard RW, Sharp F (eds). Royal College of Obstericians and Gynecologists, London pp433-440, 1988.

13. Aaltonen LA, Peltomaki P, Leach FS, Sistonen P, Pylkanen L, Mecklin J-P, et al: Clues to the pathogenesis of familial colorectal cancer. Science 260: 812-816, 1993.

14. Ionov Y, Peinado MA, Malkhosyan S, Shibata D and Perucho M: Ubiquitus somatic mutations in simple repeated sequences reveal a new mechanism for colonic carcinogenesis. Nature 363: 558-561, 1993.
15. Thibodeau SN, Bren G and Schaid D: Microsatellite instability in cancer of proximal colon. Science 260: 816-819, 1993.

16. Risinger JI, Berchuck A, Kohler MF, Watson P, Lynch HT and Boyd J: Genetic instability of microsatellites in endometrial carcinoma. Cancer Res 53: 5100-5103, 1993.

17. Yee CJ, Roodi N, Verrier CS and Parl FF: Microsatellite instability and loss of heterozygosity in breast cancer. Cancer Res 54: 1641-1644, 1994.

18. Shridhar V, Siegfried J, Hunt J, Alonso MM and Smith DI: Genetic instability of microsatellite sequences in many nonsmall cell lung carcinomas. Cancer Res 54: 2084-2087, 1994.

19. Kiaris H, Spandidos DA, Jones AS and Field JK: Loss of heterozygosity and microsatellite instability of the H-ras gene in cancer of the head and neck. Int J Oncol 5: 579-582, 1994.

20. Field JK, Kiaris H, Howard P, Vaughan ED, Spandidos DA and Jones AS: Microsatellite instability in squamous cell carcinoma of the head and neck. Br J Cancer 75: 1065-1069, 1995.

21. Schlotterer C and Tautz D: Slippage synthesis of simple sequence DNA. Nucleic Acids Res 20: 211-215, 1992.

22. Shibata D, Peinado MA, Ionov Y, Malkhosyan S and Perucho M: Genomic instability in repeated sequences is an early somatic event in colorectal tumorigenesis that persists after transformation. Nature Genet 6: 273-281, 1994.

23. Markowitz S, Wang J, Myeroff L, Parsons R, Sun LZ, Lutterbaugh J, et al: Inactivation of the type II TGF- $B$, receptor in colon cancer cells with microsatellite instability. Science 268: 1336-1338, 1995.

24. Parsons R, Li G-M, Longley MJ, Fang W, Papadopoulos N, Jen J, de la Chapelle A, Kinzler KW, Vogelstein B and Modrich P: Hypermutability and mismatch repair deficiency in $\mathrm{RER}^{+}$ tumour cells. Cell 75: 1227-1236, 1993.

25. Loeb LA: Microsatellite instability: Marker of a mutator phenotype in cancer. Cancer Res 54: 5059-5063, 1994.

26. Parsons R, Li G-M, Longley M, Modrich P, Liu B, Berk T, Hamilton SR, Kinzler KW and Vogelstein B: Mismatch repair deficiency in phenotypically normal human cells. Science 268 : 738-740, 1995. 